\title{
Dilemas de la representación democrática
}

Luz Mery Rojas Cárdenas

Universidad Pontificia Bolivariana, Colombia

luzm.rojas@upb.edu.co

Manuel Alcántara, Porfirio Cardona-Restrepo, Dilemas de la representación democrática, Medellín, Colombia, Tirant Lo Blanch/Universidad Pontificia Bolivariana, 2020.

La representación política ha sido un elemento determinante en el desarrollo de las democracias contemporáneas, con especial influencia en la teoría política, las instituciones y el comportamiento de los individuos. Durante los últimos años los desafíos de un mundo interconectado por las redes sociales virtuales, la inmediatez del internet y la incertidumbre generada por los constantes cambios sociales y económicos, evidenciaron la necesidad de reconocer las relaciones políticas de una manera diferente a la que tradicionalmente se concebían; situación que se profundizó con los acontecimientos relacionados con la Covid-19.

Dilemas de la representación democrática, parte del principio de que la representatividad es la piedra angular de todo el edificio democrático, pero sufre cierto desgaste que implica innegables retos o desafíos que desembocan en algunos dilemas de la representación actual. Los coordinadores académicos del texto, Manuel Alcántara y Porfirio Cardona-Restrepo, abordan estas cuestiones a partir de tres secciones claramente delimitadas con acercamientos metodológicos distintos de (c) (1) (9) 4.0 Internacional 
orden cualitativo y cuantitativo, con los que buscan acercarse a la respuesta de la pregunta central: ¿cuáles son esas razones para hablar de un de declive o reconversión de la democracia liberal como un sistema legítimo del ordenamiento político en tiempos de cambio y de conflicto?

En la primera sección, se presentan los marcos teóricos y contextuales de la representación democrática. Los autores abren el debate sobre el por qué ocurre este fenómeno, es decir, ¿De qué se trata la representación democrática? Aspecto que despliega el profesor Subirat, y que abre paso a otras disertaciones, esta vez de la mano del profesor Fernando Barrientos quien abre dos importantes interrogantes: ¿Está la representación democrática en crisis o, en su defecto, es imposible su representación? ¿Qué elementos están demostrando esa crisis y cómo se evidencian esos dilemas?

La respuesta a estas preguntas a medida que avanza el texto va evidenciando cómo estos cambios surgen a partir de una importante volatilidad electoral en la que un gran número de votantes buscan de manera reiterada vehículos representativos alternativos, y sugiere con ello una insatisfacción con la calidad de la representación. Esto explica el ascenso de los candidatos outsiders que se toman la política mundial como consecuencia de las nuevas formas de comunicación política y la desafección ciudadana. Asimismo, se constata el crecimiento de regímenes políticos que alteran los principios considerados esenciales de una democracia, es el caso del avance del populismo en América Latina donde, como lo advierten las profesoras Angélica Abad Cisneros y Alejandra Salinas, el voto hacia candidatos y partidos populistas lleva 
implícito el reclamo por un ejercicio de la representación que privilegie los resultados antes que el proceso y que las instituciones.

Lo anterior sumado a los nuevos códigos y lenguajes en los que navega la democracia actualmente: sesgos de confirmación, razonamiento motivado, negacionismos, la posverdad, noticias alternativas, democracia sentimental o emocional en lugar de la democracia procedimental y racional, que afectan la percepción del ciudadano que no decide muchas veces de forma racional y autónoma en sus preferencias electorales o políticas. El hecho de que en el ejercicio de la democracia se acostumbre a pasar emociones engañosas por hechos objetivos, causa en el plano político un fenómeno que deslegitima la institución como tal. Este asunto se encuentra documentado en el capítulo VI escribe el profesor Porfirio CardonaRestrepo junto con el profesor Andrés Felipe Arango.

Finalmente, esta sección cierra poniendo en consideración el carácter polisémico de la democracia representativa y su adjetivación: crisis democrática, malestar de la democracia, democracia desgastada, restringida, sentimental, sitiada o asediada, entre otros. Lo que podemos decir de todo esto es que existen unos síntomas que muestran que pasa algo con la democracia, particularmente con cuatro aspectos de la política que se vincula con la dimensión electoral de la democracia como son la libertad, la igualdad, la confianza y la identidad, como lo destaca el profesor Manuel Alcántara en el capítulo uno.

La segunda sección se ocupa del cómo del fenómeno, es decir, una explicación causal de la representación democrática a partir de varios estudios comparados en temas que incluyen el diseño institucional de la democracia representativa sobre todo cuando se debe acatar o cambiar las reglas institucionales. Allí se analiza por 
parte de José Manuel Rivas, los casos de Hugo Chávez en Venezuela y José Luis Rodríguez Zapatero en España.

Hacia adelante se presentan los efectos de la revocatoria de mandato incorporado en varias constituciones latinoamericanas desde la década de 1990 para definir la utilidad real del mecanismo y como herramienta de especulación electoral o de venganza en manos de los contendientes políticos. Lo cual se complementa desde el análisis cuantitativo con la presentación del grado de superposición ideológica entre los partidos de América Latina en el momento actual, calculado desde el índice de superposición ideológica con datos del Proyecto de Élites Parlamentarias de América Latina de la Universidad de Salamanca (PELA).

Estos análisis cuantitativos, incorporan nuevas miradas con los aportes de Iván Llamazares Valduvieco y Mariana Sendra quienes, mediante el uso de técnicas estadísticas multinivel, examinan los efectos de la autoridad regional sobre la heterogeneidad programática de los electorados de los partidos políticos hacen una revisión de la situación del viejo continente.

Por último, en esta sección, Emily Carty y Mariano Torcal destaca la estructura del activismo político en América Latina donde se muestra el cambio de las actividades de participación propiciadas por las élites nacionales y, sobre todo, locales para dar respuesta a una creciente demanda de participación ciudadana directa en la toma de decisiones democráticas.

Ya en la tercera y, última sección, se presentan dos estudios de caso en donde se exhibe lo complejo que resulta la representación en democracias cuando hay altos índices de violencia o de debilidad de los Estados para garantizar el imperio de la ley como en el contexto colombiano con el análisis de Javier Duque Daza y el mexicano 
con el profesor Juan Mario Solis, a diferencia de las democracias industrializadas donde la crisis está en función de factores económicos.

Algunas preguntas que se suscitan acá, son: ¿Qué ocurre en aquellos países en los que la democracia es deficitaria y el nivel de estatalidad es muy bajo, en los que existen órdenes de ilegalidad y organizaciones criminales que le disputan al Estado el uso de la fuerza y han logrado permear a los sectores productivos, a las diversas esferas de la sociedad, parlamentos, congresos, partidos políticos o asambleas representativas? y ¿Qué patrones muestran los asesinatos de políticos en comicios electorales por parte de las bandas criminales a quienes les resultan incomodos para sus intereses?

Es preciso indicar que, aunque no se desarrolla en el libro y solo se hace de manera enunciativa, es el señalamiento de los acontecimientos ligados a la pandemia, que van a ejercer mayor presión sobre la democracia representativa. La pandemia amplifica el problema: recesión económica, medidas restrictivas, aumento de la desigualdad, crisis de liderazgo político. Ese sería un nuevo capítulo, además de otros, para seguir profundizando y contribuyendo con la calidad del debate público en este tema en particular, y en la consolidación, claro está, de la ciencia política cuando las redes y comunidades académica se congregan.

El texto presenta unos síntomas que muestran poco a poco la implosión de la democracia representativa en medio de una expansión de una cultura y sociedad cada vez más laberíntica, es decir, con ciento de bifurcaciones a los que hay que atender. El dilema estaría en cómo representar en medio de dicha complejidad y cuando se anuncia su caída como gran paradigma de Occidente. El texto no se ocupa de responder a cuál será la nueva forma de ordenamiento de lo político y su E-ISSN 2395-8464 https://doi.org/10.18234/secuencia.v0i0.1977 


\section{Luz Mery Rojas Cárdenas}

legitimidad democrática para responder a la compleja situación contemporánea, tampoco de llegar a una conclusión taxativa, más bien expone los dilemas y a repensar la relación de los ciudadanos-política y sus intermediaciones en un contexto concreto como el de hoy.

El sentido y la coherencia interna es la mayor virtud del texto como lo indica en el prólogo Marcelo Cavarozzi, y de paso se constituye en una lectura calve para politólogos y estudiosos de las ciencias sociales sobre un tema como la presentación política en tiempos de crisis. 